\title{
Eric Liou
}

- Undergraduate degree in Dentistry from the School of Dentistry, Taipei Medical University, Taipei, Taiwan.

- Graduate degree from the Department of Orthodontics and Craniofacial Dentistry at Chang Gung Memorial Hospital, Taipei, Taiwan.

- Master in Surgery, University of Illinois, Chicago, USA.

- Assistant Professor and Director of the Research and Development Committee of the Faculty of Dentistry at Chang Gung Memorial Hospital,

Taipei, Taiwan.

- Orthodontist at the Department of Orthodontics and Craniofacial Dentistry at Chang Gung Memorial Hospital, Taipei, Taiwan.

- President, Taiwan Association of Cleft Lip and Palate.

- Winner, Best Clinical Article, AJODO, 1998.

- 28 international publications, 5 book chapters, 132 participations in lectures and courses overseas, 5 international patents.

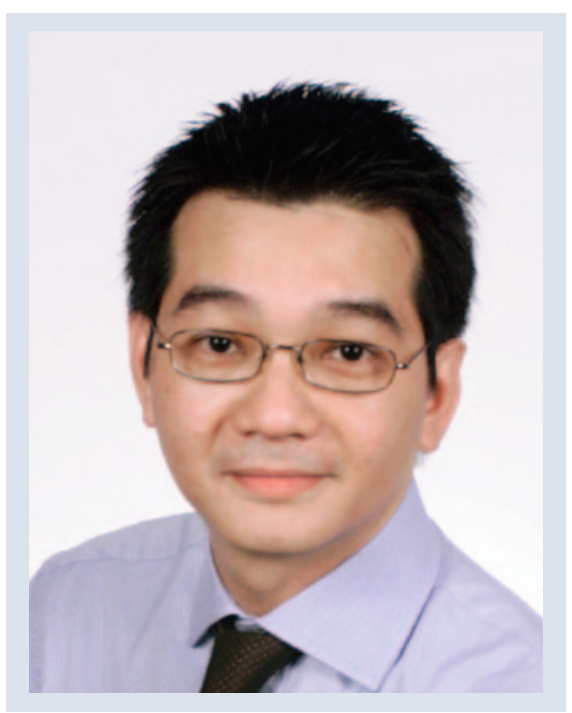

It's my pleasure to introduce Professor Eric Liou, from Taipei, Taiwan. He is one of the most important members of the world new generation of orthodontists, who will be in Brazil for the first time in October 2009, for a speech at the $7^{\text {th }}$ Brazilian Association of Orthodontists Meeting that will be held in Brasilia-DF. We first met in Dallas, in 1998, during the American Association of Orthodontists annual meeting. At that time he had just won the Dewel Award, given to the best clinical article of the year published at the AJODO. Since there I've followed his brilliant work, where he has accomplished several clinical and experimental researches whose results have given rise to some controversial and have generated a lot of interest at the international orthodontic community for its originality and vanguard. His fields of interest involve osteogenic distraction, skeletal anchorage and mechanisms to accelerate orthodontic movement. However, without doubt, one of the most important topics, frequently present in his presentations is the new protocol for maxillary protraction called Alt-RAMEC, used both for patients with or without cleft lip and palate. This is the subject of this interview conducted by me and by three other important Brazilian orthodontists, who have a lot of experience in rapid maxillary expansion and in the treatment of cleft lip and palate patients: Dr. Omar Gabriel da Silva Filho, Dr. Daniela Gamba Garib and Dr. Gerson Ulema Ribeiro.

Enjoy the reading!!!! 
You state that the Alt-RAMEC protocol opens the circumaxillary sutures and shows an extreme orthopedic effect in patients with cleft lip and palate, where you had an average of $5.8 \mathrm{~mm}$ of maxillary protraction. This protocol could be used with the same efficacy in patients without fissures? Daniela Gamba Garib and Omar Gabriel da Silva filho

The protocol of alternate rapid maxillary expansions and constrictions (Alt-RAMEC) is either effective in patients with or without cleft lip and palate. The Alt-RAMEC was developed in 2005 for the growth of a hypoplastic maxilla not only for the growing patients with cleft lip and palate $^{18}$, but also for those without cleft ${ }^{15,16}$. The clinical devices and protocol are exactly the same for both groups of patients. The devices are the
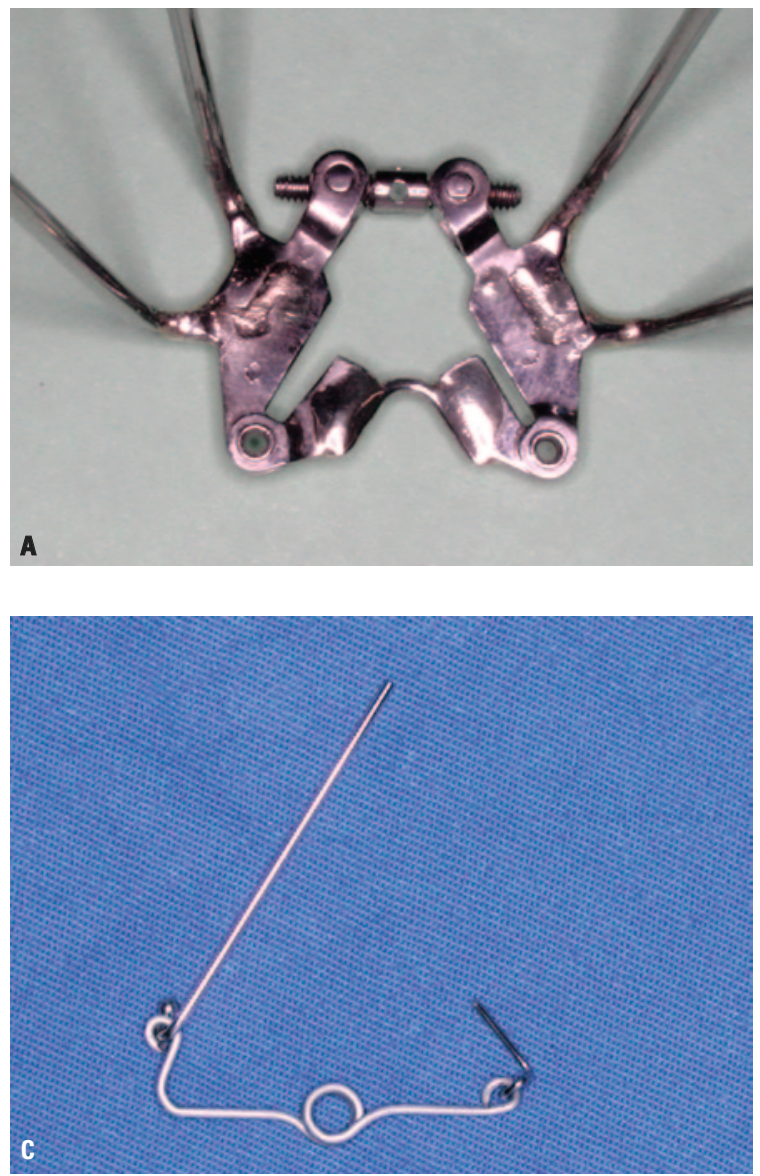

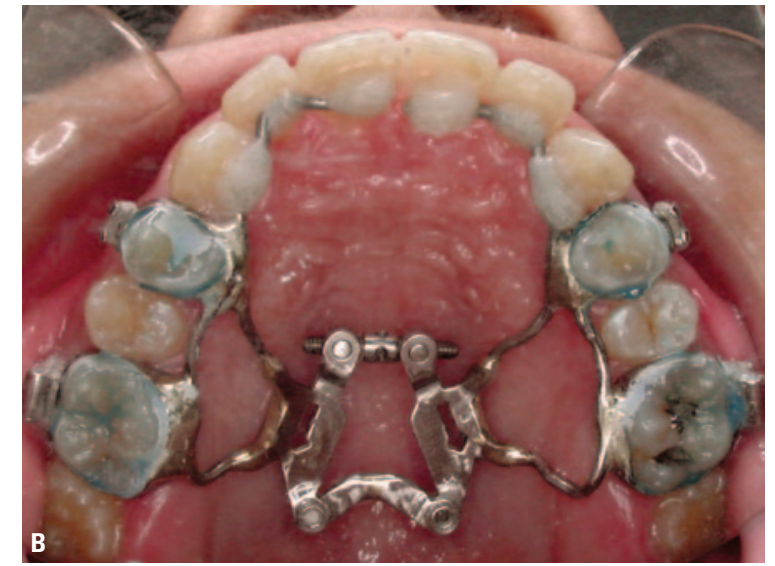

double-hinged expander (US Patent No. 6334771 B1) (Fig. 1A, B) and the intraoral $\beta$-Ti maxillary protraction springs (US patent $6273713 \mathrm{~B} 1$ ) (Fig. 1C, D). The complete protocol involves 7 weeks of Alt-RAMEC (Tab. 1). It should always keep the expander opened at the end of the protocol because an expanded maxilla allows a greater amount of maxillary protraction than an unexpanded maxilla, and the expanded space between the central incisors could be saved for relieving anterior crowding or for compensating dental effects, such as the proclined maxillary incisors due to the protraction. In comparison between the growing patients with and without cleft lip and palate, the efficacy of this protocol for the maxillary orthopedic protraction is similar and has no significant difference (Tab. 2).

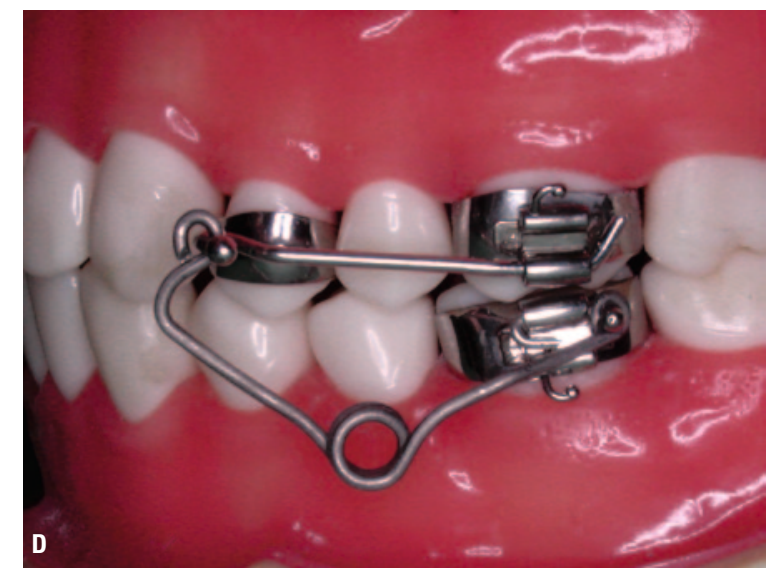

FIGURE 1 - A, B) Double-hinged expander, C, D) intraoral $\beta$-Ti maxillary protraction spring. 
TABLE 1 - Clinical protocol for alternate rapid maxillary expansions and constrictions (Alt-RAMEC).

\begin{tabular}{|ccc|}
\hline $\begin{array}{c}\text { ALTERNATE } \\
\text { WEEKLY } \\
\text { SEOUENCE }\end{array}$ & $\begin{array}{c}\text { WEEKLY AMOUNT OF EX- } \\
\text { PANSION/CONSTRICTION }\end{array}$ & $\begin{array}{c}\text { DAILY AMOUNT } \\
\text { OF ACTIVATION }\end{array}$ \\
\hline Expansion & $7 \mathrm{~mm}$ & $1 \mathrm{~mm}$ \\
\hline Constriction & $7 \mathrm{~mm}$ & $1 \mathrm{~mm}$ \\
\hline Expansion & $7 \mathrm{~mm}$ & $1 \mathrm{~mm}$ \\
\hline Constriction & $7 \mathrm{~mm}$ & $1 \mathrm{~mm}$ \\
\hline Expansion & $7 \mathrm{~mm}$ & $1 \mathrm{~mm}$ \\
\hline Constriction & $7 \mathrm{~mm}$ & $1 \mathrm{~mm}$ \\
\hline Expansion & $7 \mathrm{~mm}$ & $1 \mathrm{~mm}$ \\
\hline
\end{tabular}

TABLE 2 - Comparison of the amount of maxillary protraction at A point between the growing patients with cleft lip and palate and those without (regular Class III growing patients).

\begin{tabular}{|c|c|c|c|}
\hline & $\begin{array}{l}\text { GROWING } \\
\text { PATIENTS } \\
\text { WITH CLEFT } \\
\text { LIP AND } \\
\text { PALATE (N=10) }\end{array}$ & $\begin{array}{l}\text { REGULAR CLASS } \\
\text { III GROWING } \\
\text { PATIENTS (N=13) }\end{array}$ & STATISTICS \\
\hline $\begin{array}{c}\text { maxillary } \\
\text { protraction at } \\
\text { A point }(\mathrm{mm})\end{array}$ & $5,8 \pm 2,3$ & $5,3 \pm 1,1$ & n.s. \\
\hline
\end{tabular}

n.s. = no significant difference.

Could your technique of effective maxillary orthopedic protraction be implemented using conventional screws, like those used in Haas or Hyrax appliances? What is the main difference between the double-hinged expander used in your protocol and the classical one? Daniela Gamba Garib and Ricardo Machado Cruz

The Hyrax and the double-hinged expanders could be both effective for the opening of circumaxillary sutures under the protocol of Alt-RAMEC. The key is the protocol of Alt-RAMEC rather than the types of expander. However, in terms of the extent of anterior displacement after Alt-RAMEC, the double-hinged expander has been revealed superior to the other types of expander. Several types of rapid maxillary expander have been used for the purpose of maxillary protraction. They are the fan-typed ${ }^{14,25}$ or Hyrax-typed built with two acrylic resin halves ${ }^{7}$, splints ${ }^{20}$, or in a hygienic design $^{2}$. These appliances expand and rotate the maxilla outward in a $\mathrm{V}$-shaped manner ${ }^{28}$.

The center of rotation is located around the posterior nasal spine ${ }^{3,13}$. The expansion force is distributed not only in the maxilla but also extends into the circumaxillary structures ${ }^{4,12}$. It is postulated that this entails bone resorption behind the maxilla and consequently results in posterior displacement of maxilla ${ }^{2}$ (Fig. 2A, B). On the contrast, it is postulated as well that this entails the circumaxillary structures such as pterygpoid plates to displace the maxilla forward ${ }^{8,9}$ (Fig. 2C). These two assumptions explain why some of the clinical studies on Hyrax-typed expanders reported an anterior displacement of maxilla ${ }^{1,7,30}$, while some others reported no significant displacement ${ }^{22,24}$ or even a posterior displacement of maxilla ${ }^{5,23}$. The posterior displacement of maxilla compromises the maxillary protraction in Class III patients.

The double-hinged rapid maxillary expander is developed for a greater anterior displacement of maxilla ${ }^{17,18}$. Its configuration is similar to a Wappliance and has 2 hinges of rotation. It consists of a jackscrew in the center, two bolts holding the screw, a body holding the bolts at the anterior and two hinges of rotation at the posterior (Fig. 1A, B). It expands and rotates each half of the maxilla outward through the two hinges of rotation. This model of expansion entails forward rotation of maxilla with less chance of bone resorption behind the maxillary tuberosities (Fig. 2D), and this has been verified in an experimental study in 14 cats that the double-hinged expander significantly displaced the maxilla more anteriorly than the Hyrax expander ${ }^{10}$ (Tab. 3). It is therefore, in

TABLE 3 - Comparison of the anterior displacement of maxilla between Hyrax and double-hinged expanders in an experimental model in cats ${ }^{10}$.

\begin{tabular}{|c|c|c|c|}
\hline & $\begin{array}{c}\text { HYRAX } \\
\text { EXPANDER } \\
(N=7)\end{array}$ & $\begin{array}{l}\text { DOUBLE- } \\
\text { HINGED EX- } \\
\text { PANDER (N=7) }\end{array}$ & STATISTICS \\
\hline $\begin{array}{c}\text { Anterior } \\
\text { displacement } \\
\text { of maxilla } \\
(\mathrm{mm})\end{array}$ & $1,6 \pm 0,9$ & $2,8 \pm 1,5$ & $p<0,01$ \\
\hline
\end{tabular}




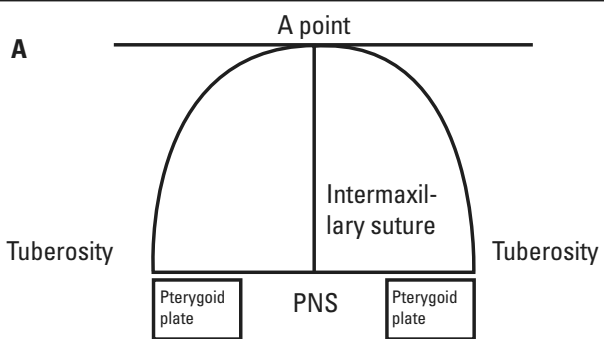

A point:

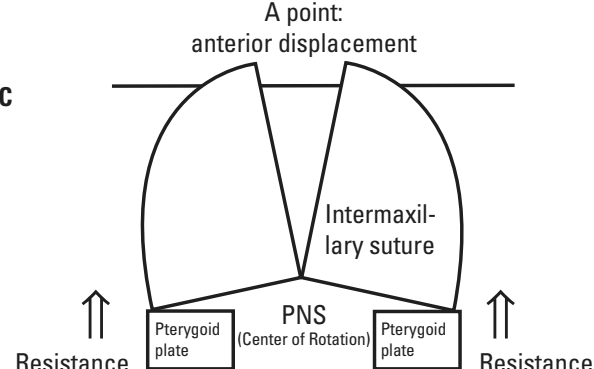

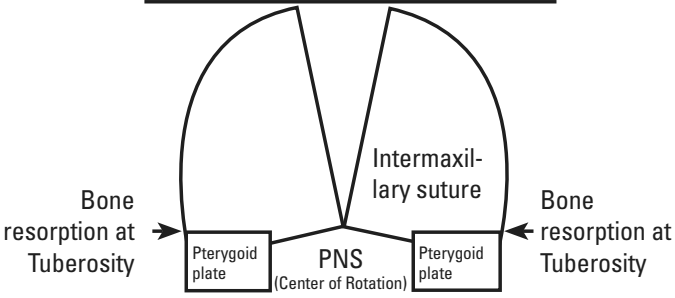

A point:

D

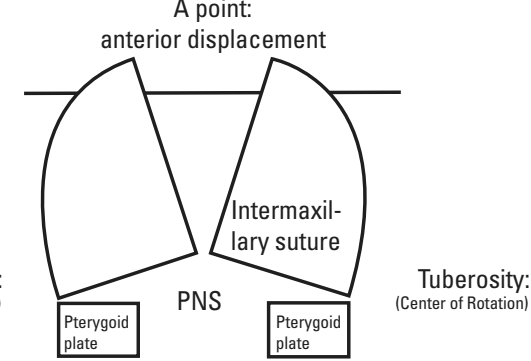

FIGURE 2 - Schematic illustrations of the postulated maxillary displacement after rapid maxillary expansion. A) The maxilla before expansion: the semicircles represent the right and left maxillae; the rectangles represent the pterygoid plates. B) Posterior displacement of the maxilla after expansion by a Hyrax expander: each half of the maxilla rotates outward and backward around the posterior nasal spine (PNS), which entails bone resorption behind the maxillary tuberosities and results in posterior displacement of maxilla. C) Anterior displacement of the maxilla after expansion by a Hyrax expander: each half of the maxilla rotates outward and backward around the PNS, which entails the circumaxillary structures to displace the maxilla forward and results in anterior displacement of maxilla. D) Anterior displacement of the maxilla after expansion by a double-hinged expander: each half of the maxilla rotates outward and forward around the maxillary tuberosities, which geometrically results in anterior displacement of maxilla and less chance of bone resorption behind the maxillary tuberosities.

terms of the anterior displacement of maxilla, a double-hinged maxillary expander is superior to the other types of expander for the treatment of a hypoplastic maxilla in growing Class III or cleft patient.

To clinically setup the double-hinged expander in a patient, maxillary first premolars and molars are banded and maxillary impression is taken. The double-hinged expander is then placed and oriented on the maxillary cast so that its screw is perpendicular to the intermaxillary suture no matter it is for a patient with cleft lip and palate or regular Class III patient. The expander is than soldered to the molar and premolar bands. Two anterior extension arms (0.051-inch stainless steel wires) extending bilaterally from the premolar bands toward the central incisors are soldered to the premolar bands (Fig. 1B). The premolar and molar bands and the anterior extension arms are sandblasted before cementation. After cementa- tion of the expander, the anterior extension arms are bonded to the anterior teeth with composite resin (Fig. 1B). One day after cementation, the double-hinged expander is activated according to the protocol of Alt-RAMEC.

Is it possible to install facial masks instead of the pair of TMA intraoral springs or do you utilize both methods simultaneously for maxillary protraction? Do you think the results in maxillary protraction would be the same? Do you have any clinical or experimental evidences comparing the two methods? Ricardo Machado Cruz

The efficiency of maxillary protraction depends mostly on the opening of circumaxillary sutures. An adequate opening of the circuumaxillary sutures is the prerequisite for a good amount of maxillary protraction, no matter it is a facemask, $\beta$-Ti maxillary protraction spring, or combination of a 
facemask and $\beta$-Ti maxillary protraction spring. Facemask, modified protraction headgear, or heavy Class III elastics are the most frequent used devices for maxillary protraction. Their efficiency in maxillary protraction has been well documented ${ }^{7,20,21,27}$. By applying the protraction force $30^{\circ}$ down anteriorly, they are able to direct a forward and downward protraction force so that the maxilla could be protracted through the center of resistance of the maxilla. However, they are extraoral devices and dependent largely on patient's compliance for their efficiency.

On the other hand, the $\beta$-Ti maxillary protraction spring ${ }^{18}$ has been the only intraoral device that delivers reasonable orthopedic force for maxillary orthopedic protraction. Its efficiency is independent of patient's compliance. However, it is a custommade device and has the inherent disadvantages that most of the intraoral springs have. It breaks sometimes during treatment due to the material fatigue, and mechanically it is almost impossible

TABLE 4 - Comparison of the amount of maxillary protraction at A point between the $\beta$-Ti maxillary protraction spring ${ }^{18}$ and facemask ${ }^{26}$ under the same protocol of Alt-RMEC in growing patients with cleft lip and palate.

\begin{tabular}{|c|c|c|c|}
\hline & $\begin{array}{c}\beta-T I \\
\text { MAXILLARY } \\
\text { PROTRACTION } \\
\text { SPRING (N=10) }\end{array}$ & $\begin{array}{c}\text { FACEMASK } \\
(\mathrm{N}=20)\end{array}$ & STATISTICS \\
\hline $\begin{array}{l}\text { maxillary } \\
\text { protraction } \\
\text { at A point } \\
(\mathrm{mm})\end{array}$ & $5,8+2,3$ & $5,01 \pm 1,48$ & n.s. \\
\hline
\end{tabular}

n.s. = no significant difference. to deliver a protraction force through the center of resistance of the maxilla due to its intraoral design. The orthopedic mechanics of the $\beta$-Ti maxillary protraction spring is by breaking down the biting force into a forward component of force that protracts the maxilla, and an upward component of force that rotates the mandible backward. But at the same time it also tilts the palatal plane upward and opens the bite at the anterior. The upward tilting of palatal plane and bite opening are not usual in the application of facemask or modified protraction headgear.

Therefore the $\beta$-Ti maxillary protraction spring is indicated in cases with overclosure of mandible and anterior overbite. The maxillary protraction spring is contraindicated in cases with a high mandibular plane angle or anterior open bite Class III patients. Facemask or modified protraction headgear could be a more suitable device for such cases. In comparison of the efficiency between the $\beta$-Ti maxillary protraction spring and facemask under the same protocol of Alt-RMEC, our clinical studies (Tab. 4) for growing patients with cleft lip and palate have revealed that the maxillary protraction by using facemask was $5.01 \pm 1.48 \mathrm{~mm}$ in 6 months ${ }^{26}$, whereas it was $5.8 \pm 2.3 \mathrm{~mm}$ in 3 months ${ }^{18}$ (Fig. 3).

\section{Have you observed any nasal bone fracture during the execution of the alt-RAMEC proto- col? Omar Gabriel da Silva Filho \\ Until now, we have not seen or observed ex- perimentally and clinically any nasal bone or other}
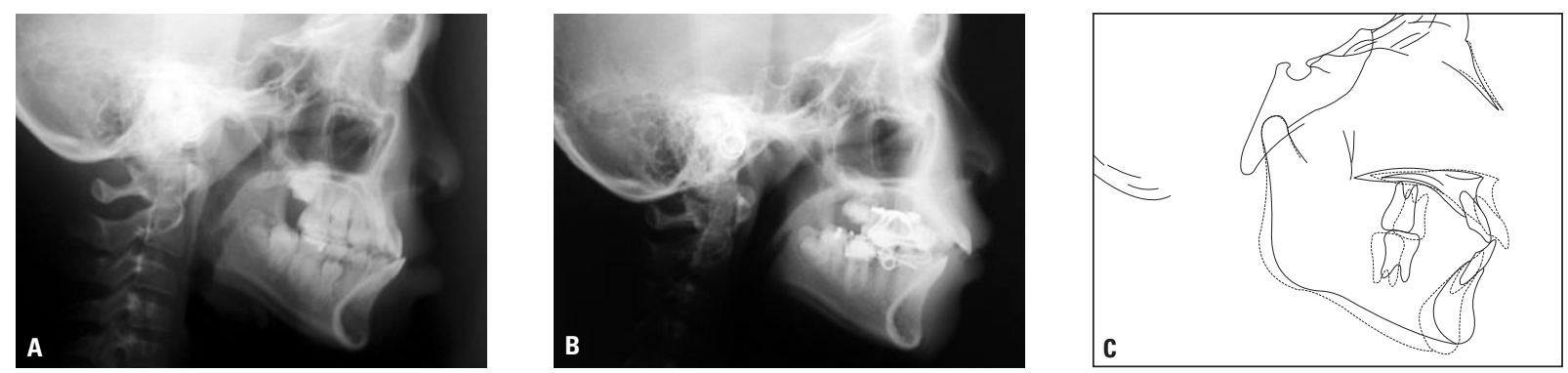

FIGURE 3 - The maxilla was protracted for $6.5 \mathrm{~mm}$ by using intraoral $\beta$-Ti maxillary protraction springs. A) Lateral cephalogram before protraction, B) lateral cephalogram after the protraction, C) cephalometric superimposition. 
facial bone fracture during or after the protocol of Alt-RAMEC. Anatomically, the nasal bones articulate with the frontonasal processes of maxilla and the frontal bones. The sutures surrounding nasal bones are the internasal nasal, frontonasal, and the nasomaxillary sutures. Sutures are the tissues absorbing stress and strain whenever forces are applied on bones. Cracks or fractures could only happen whenever the sutures surrounding the nasal bones have fused.

In our experimental study, we grossly examined the skull and facial bone specimen of 6 cats underwent 5 weeks of Alt-RAMEC ${ }^{29}$. We detected the sutures surrounding the nasal bones were opened $100 \%$ quantitatively in the internasal and nasomaxillary sutures and 58.3\% in the nasofrontal suture. No crack or fracture line in the nasal bone or other facial bones was detected (Fig. 4).

Clinically, we have revealed in a clinical cephalometric study that, in addition to the maxilla, the nasal bones were displaced after Alt-RAMEC and then protracted anteriorly by the maxillary protraction springs ${ }^{18}$. Among those cases, some reported short term discomforts in the regions of nasal bones and zygomatic key-ridges during the period of Alt-RAMEC but not in the period of maxillary orthopedic protraction. The discomfort and displacement indicated that the sutures surrounding nasal bones were being disarticulated, or the nasal bones cracked or even fractured. However the clinical evidences indicated no cracks or fractures in the nasal bones. No compression pain, skin bruise, or discoloration, has been observed or reported in any of the patients. More direct and further clinical evidences also have been revealed in our current prospective cone beam CT study in 14 patients who had undergone 7 weeks of AltRAREC, in which no fracture or crack line was observed in any of the circumaxillary facial bones, including the nasal bones (Fig. 5).

However, the concerns of nasal or other facial bones fracture or crack during the period of AltRAMEC could be a serious issue, especially in cases whose circumaxillary sutures have begun to fuse or are fused.
The alt-RAMEC technique disarranges and weakens all maxillary sutures, requiring always the maintenance of the integrity of the periosteum in order to prevent foreign cells to colonize the bone sutural space. If this problem occurs, there could be the formation of an osteoarthrosis, a pseudo-articulation formed by fibrous tissue. What would be your approach to this problem (pseudo-articulation) if this happens? Gerson Luiz Ulema Ribeiro

This is a question under the assumption if the circumaxillary sutures are over expanded and the integrity of a suture or periosteum is ruptured so that foreign cells invaginate and colonize in the suture resulting in osteoarthrosis or pseudo-articulation. This could be a serious concern whenever a suture is intentionally over expanded and exceeded the biological and physiological limitations of a suture. However, to the limit of my knowledge, the biological and physiological limitations of a suture have not been reported before.

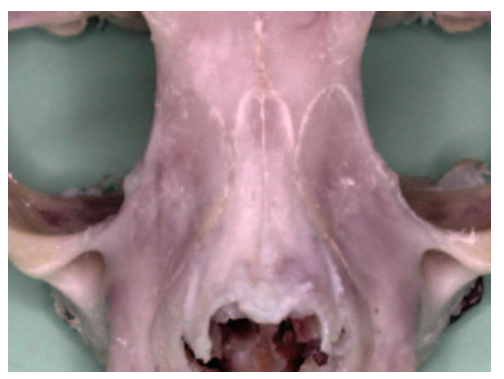

FIGURE 4 - No crack or fracture line in the nasal bone or other facial bones after 5 weeks of Alt-RAMEC was detected in an experimental study in cats ${ }^{29}$

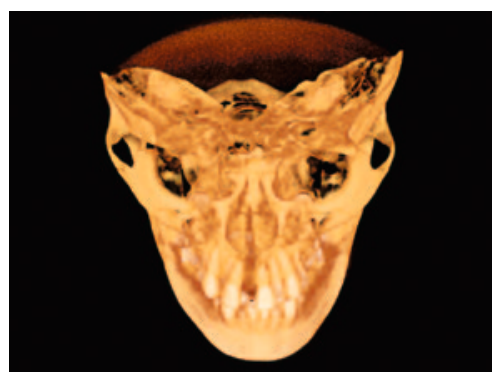

FIGURE 5 - The 3D cone beam CT image reveals no fracture or crack line after 7 weeks of Alt-RAMEC in the circumaxillary facial bones of a girl. 
The suture is an osteogenic and osteolytic tissue that allowed for a certain degree of expansion and constriction. Within the biological and physiological limitations, expansion of a suture leads to bone formation, and constriction leads to bone resorption. This phenomenon also has been referred as the sutural distraction osteogenesis and osteolysis, respectively, that resembles the callus distraction osteogenesis or osteolysis in the long bone ${ }^{19}$. For the callus distraction osteogenesis in long bone, it has been revealed that the optimal (biological and physiological) rate of distraction is $1 \mathrm{~mm} /$ day, more than $1 \mathrm{~mm}$ /day of distraction results in osteoarthrosis, and less than $1 \mathrm{~mm} /$ day results in premature
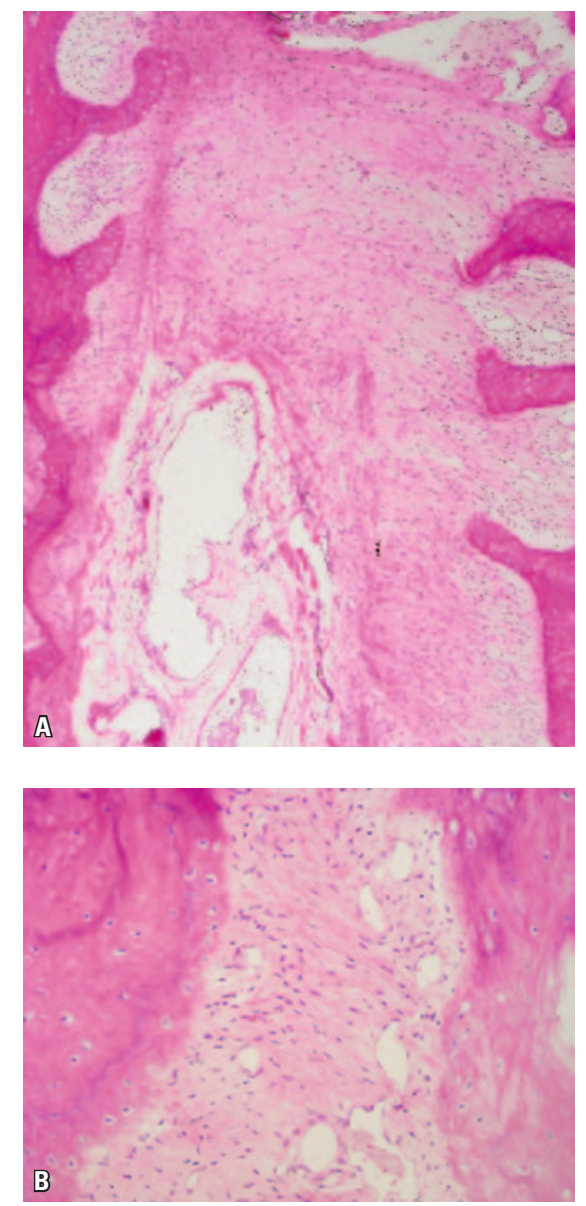

FIGURE 6 - No foreign cells invagination, colonization, steoarthrosis, and over growth of osteoid in the circummaxillary sutures after 5 weeks of Alt-RAMEC in experimental study in cats ${ }^{29}$. A) intermaxillary suture, B) zygomaticomaxillary suture. consolidation of the distraction site ${ }^{11}$. It also has been considered that $1 \mathrm{~mm} /$ day is the biological, physiological, and optimal rate for rapid maxillary suture expansion ${ }^{7,8,9}$. The optimal rate of expansion or distraction for any osteogenetic tissue, such as suture or callus, is $1 \mathrm{~mm} /$ day. In our experimental study on Alt-RAMEC ${ }^{29}$, we opened and constricted the maxilla $1 \mathrm{~mm} /$ day and we did not observed foreign cells invagination, colonization, and osteoarthrosis in any of the circummaxillary sutures (Fig. 6). The daily expansion or constriction of a suture should be biologically and physiologically confined within $1 \mathrm{~mm} /$ day.

How long does it take to correct the sagittal maxillary deficiency after the alt-RAMEC protocol? Omar Gabriel da Silva Filho

No matter it is for growing patients with cleft lip and palate or regular Class III growing patients, it takes 1 to 2 months to correct the sagittal maxillary deficiency by using the intraoral $\beta$-Ti maxillary protraction springs $s^{15,16,18}$. The total treatment period is 6 months, including 3 steps in sequence:

1) 7 weeks of Alt-RAMEC to loosen the maxilla.

2) 1 to 2 months of active maxillary protraction by using the intraoral maxillary protraction springs.

3) 2 to 3 months of maintenance by keeping the maxillary protraction springs intraorally without adding extra force.

Your protocol advocated 9 weeks, than 7 weeks of alternate rapid maxillary expansions and contractions with the aim of disarticulate the maxilla before its protraction. The same procedure with 3 or 5 weeks of expansion/ contraction would be less efficient? Daniela Gamba Garib and Ricardo Machado Cruz

To open the sagittally running circumaxillary sutures quantitatively enough for maxillary protraction, 3 or 5 weeks of Alt-RAMEC might be enough. However, at least 7 weeks of Alt-RAMEC would be necessary to open the coronally running circumaxillary sutures quantitatively enough for maxillary protraction.

It remains controversial to what width the ex- 
pansion should reach to disarticulate the circumaxillary sutures. Some report that $5 \mathrm{~mm}$ of expansion is well enough, while some others report at least 12 to $15 \mathrm{~mm}^{6}$. It seems that a greater amount of expansion will disarticulate the circumaxillary sutures more effectively than lesser expansion. However, to expand the maxilla beyond $15 \mathrm{~mm}$ is neither clinically practical nor acceptable to patients. It is difficult to accommodate a jackscrew longer than $15 \mathrm{~mm}$ across the palate without irritating palatal mucosa. After such an expansion, the expanded maxillary dental arch may be too wide to coordinate transversely with the mandibular dental arch. It is usually not necessary to increase the maxillary transverse dimension when the maxilla has been repositioned anteriorly. Rapid maxillary expander should be used to displace maxilla anteriorly and to disarticulate circumaxillary sutures rather than to expand maxilla transversely.

To disarticulate circumaxillary sutures without over-expansion of maxilla, the protocol of AltRAMEC is much more practical and feasible for such a performance. This is similar to the simple tooth extraction in which we repeatedly rock the tooth buccally and lingually until the tooth is disarticulated from the alveolar socket. However, the question remains controversial to how many expansions and constrictions are needed for a sufficient disarticulation of the circumaxillary sutures.

It was 9 weeks of Alt-RAMEC when we first developed the protocol for growing patients with cleft lip and palate ${ }^{18}$, then we shifted the protocol to 7 weeks for regular Class III growing patients ${ }^{15,16}$. Clinically, it has been our observation and experience that the effects of 9 weeks and 7 weeks of AltRAMEC are similar for the subsequent maxillary protraction. Experimentally, we have revealed in 12 cats that, after 5 weeks of Alt-RAMEC, the circumaxillary sutures running sagittally were significantly opened more quantitatively (94.4-100.0\%) than those running coronally (56.9-58.3\%), no matter they articulated directly or indirectly to the maxilla. The coronally running circumaxillary sutures were not opened quantitatively enough (56.9 to $58.3 \%$ ) after 5 weeks of Alt-RAMEC. It is the sutures running coronally rather than the sutures running sagittally needed to be well opened quantitatively for maxillary protraction. To open the coronal running sutures quantitatively enough for maxillary protraction, it is therefore at least 7 weeks of Alt-RAMEC would be necessary.

To examine whether the maxilla is clinically loosened enough for the protraction and to individualize the period of Alt-RAMEC needed for different patient, one could hold the maxilla with his/her fingers and rock the maxilla up and down. The patient would feel the mobility of maxilla or you could see the up and down movement of the maxilla once the Alt-RAMEC has loosened the maxilla enough.

\section{Considering that successive expansions and contractions could lead to a healing process that will form a very dense new bone in the suture, what would you do if it would be nec- essary another rapid maxillary expansion in the future? Gerson Luiz Ulema Ribeiro}

The formation of a very dense new bone or osteoarthrosis (no new bone formation) in an expanded suture is the two opposite extremities. We did not observe these two extremities in our experimental studies in cats. All the circumaxillary sutures were intact grossly after 5 weeks of AltRAMEC $^{29}$. No suture disruption or overgrowth of osteoid has been observed histologically (Fig. 6). The fibrous tissue and fibroblasts were stretched in the direction of expansion and constriction, and the blood vessels dilated, and the osteoid and resting lines lay along the edges of the sutures (Fig. 6). The bone remodeling (osteogenesis by osteoblasts, and osteolysis by osteoclast) in a suture was kept within the biological and physiological limitation under $1 \mathrm{~mm}$ /day of suture expansion or constriction, although the circumaxillary sutures became significantly wider after 5 weeks of Alt-RAMEC.

By using rapid maxillary expansion and facemask, it has been advised that the timing to protract the maxilla is between ages 6 to $8^{7,20,21,27}$. However, to protract the maxilla between ages 6 to 8 is too early and would possibly need a second time of 
protraction due to the growth of mandible. Our policy to avoid the second maxillary protraction is to protract the maxilla as late as possible so that the adverse effects of mandibular growth could be the least. The optimal timing therefore is right before the fusion of circumaxillary sutures. Alt-RAMEC is a technique developed for this purpose. Our clinical studies have revealed that the optimal timing for maxillary protraction, either for a growing patient with cleft lip and palate or regular Class III patient, is at the cervical vertebrate stage 2 (CVS 2). It is the beginning of puberty, around the ages of 11 13 in girls and ages of 13 15 in boys.

Is the result of this alt-RAMEC protocol stable, independently of the fissure, or there is a difference when this protocol is applied in patients without fissure? Omar Gabriel da Silva Filho

The treatment results by Alt-RAMEC and maxillary protraction have been revealed stable. Orthodontic tooth movement relapses so does the maxillary orthopedic protraction relapses. It is therefore better to over protract the maxilla as much as possible in any of the maxillary protraction techniques.

It was our clinical study that the maxilla in growing Class III patients was protracted forward $5.2 \pm 1.3 \mathrm{~mm}$ under the protocol of Alt-RAMEC and the subsequent maxillary orthopedic protraction, and the percentage of post-protraction relapse was 20 to $30 \%$ of the protraction amount. Our further study on the long term results revealed that the maxilla, including the amount of relapse, grew $3.5 \pm 1.6 \mathrm{~mm}$ further forward 5 years after the protraction. This meant the Alt-RAMEC did not jeopardize the suture growth of maxilla and the post-treatment maxillary growth compensated the amount of relapse. The total amount of maxillary growth in the horizontal direction, including the protraction, relapse, and post-treatment growth was $8.7 \mathrm{~mm}(5.2+3.5 \mathrm{~mm})$ in 5.5 years, which would be good enough for maintaining the treatment results and covering the growth of mandible in most of the growing Class III or cleft patients through their puberty.

\section{REFERENCES}

1. AKKAYA, S.; LORENZON, S.; ÜÇEM, T. T. A comparison of sagittal and vertical effects between bonded rapid and slow maxillary expansion procedures. Eur. J. Orthod., Oxford, v. 21, no. 2, p. 175-180, Apr. 1999.

2. BIEDERMAN, W.; CHEM, B. Rapid correction of Class III malocclusion by midpalatal expansion. Am. J. Orthod. St. Louis, v. 63, no. 1, p. 47-55, 1973.

3. BRAUN, S.; BOTTREL, J. A.; LEE, K. G.; LUNAZZI, J. J.; LEGAN, H. L. The biomechanics of rapid maxillary sutural expansion. Am. J. Orthod. Dentofacial Orthop., St. Louis, v. 118 , no. 3, p. 257-261, Sept. 2000.

4. CHACONAS, S. J.; CAPUTO, A. A. Observation of orthopedic force distribution produced by maxillary orthodontic appliances. Am. J. Orthod., St. Louis, v. 82, no. 6, p. 492-501, Dec. 1982.

5. COZZA, P.; GIANCOTTI, A.; PETROSINO, A. Rapid palatal expansion in mixed dentition using a modified expander: $A$ cephalometric investigation. J. Orthod., London, v. 28, no. 2, p. 129-134, June 2001.

6. HAAS, A. J. Long-term posttreatment evaluation of rapid palatal expansion. Angle Orthod., Appleton, v. 50, no. 3, p. 189-217, July 1980.

7. HAAS, A. J. Palatal expansion: Just the beginning of dentofacial orthopedics. Am. J. Orthod., St. Louis, v. 57, no. 3, p. 219-255, 1970.

8. HAAS, A. J. Rapid expansion of the maxillary dental arch and nasal cavity by opening the midpalatal suture. Angle Orthod. Appleton, v. 31, no. 2, p. 73-90, Apr. 1961.

9. HAAS, A. J. The treatment of maxillary deficiency by opening the midpalatal suture. Angle Orthod., Appleton, v. 35, no. 3, p. 200-217, July 1965 .

10. HUANG, C. T.; WANG, Y. C.; HUANG, C. S.; LIOU, E. J. Maxillary displacement after rapid maxillary expansions: An animal study. J. Taiwan Assoc. Orthod., Taipei, v. 20, no. 2, p. 19-31, 2008.

11. ILIZAROV, G. A.; LEDIOV, V. L.; SHITIN, V. P. The course of compact bone reparative regeneration in distraction osteosynthesis under different conditions of bone fragment fixation (experimental study). Eksp. Khir. Anesteziol., Moscou, v. 14 , no. 6, p. 3-12, Nov./Dec. 1969

12. $\mathbf{I T O H}, \mathrm{T}$. Photoelastic effect of maxillary protraction on the craniofacial complex. Am. J. Orthod., St. Louis, v. 88, p. 117-124, 1985

13. LEE, K. G.; RYU, Y. K.; PARK, Y. C.; RUDOLPH, D. J. A study of holographic interferometry on the initial reaction of maxillofacial complex during protraction. Am. J. Orthod. Dentofacial Orthop., St. Louis, v. 111, no. 6, p. 623-632, 1997.

14. LEVRINI, L.; FILIPPI, V. A fan-shaped maxillary expander. J. Clin. Orthod., Boulder, v. 33, no. 11, p. 642-643, 1999.

15. LIOU, E. J. An innovative technique for maxillary protraction in Class III growing patients: The effective maxillary orthopedic protraction. J. Clin. Orthod., Boulder, v. 39, p. 68-75, 2005.

16. LIOU, E. J. Effective maxillary orthopedic protraction for growing Class III patients: A clinical application simulates distraction osteogenesis. Prog. Orthod., Berlin, v. 6, no. 2, p. 154-171, 2005. 
17. LIOU, E. J.: CHEN, P. K. T. New orthodontic and orthopaedic managements on the premaxillary deformities in patients with bilateral cleft before alveolar bone grafting. Ann. R. Coll. Surg. Engl., London, v. 7, no. 3, p. 73-82, Aug. 2003.

18. LIOU, E. J.; TSAI, W. C. A new protocol for maxillary protraction in cleft patients: Repetitive weekly protocol of alternate rapid maxillary expansions and constrictions. Cleft Palate Craniofac. J., Pittsburgh, v. 42, no. 2, p. 121-127, Mar. 2005.

19. LIU, C.; SONG, R.; SONG, Y. Sutural expansion osteogenesis for management of the bony-tissue defect in cleft palate repair: Experimental studies in dogs. Plast. Reconstr. Surg., Hagerstown, v. 105, no. 6, p. 2012-2025, 2000

20. McNAMARA JR., J. A. An orthopedic approach to the treatment of Class III malocclusion in young patients. J. Clin. Orthod., Boulder, v. 21, no. 9, p. 598-608, Sep. 1987.

21. NANDA, R. Biomechanical and clinical considerations of a modified protraction headgear. Am. J. Orthod., St. Louis, v. 78 , no. 2, p. 125-139, 1980

22. PANGRAZIO-KULBERSH, V.; BERGER, J.; KERSTEN, G. Effects of protraction mechanics on the midface. Am. J. Orthod. Dentofacial Orthop., St. Louis, v. 114, no. 5, p. 484-491, Nov. 1998

23. SARVER, D. M.; JOHNSTON, M. W. Skeletal changes in vertical and anterior displacement of the maxilla with bonded rapid palatal expansion appliances. Am. J. Orthod. Dentofacial Orthop., St. Louis, v. 95, no. 6, p. 462-466, June 1989.

\section{Daniela Gamba Garib}

- Doctorate Professor of Orthodontics - HRAC/FOB-USP.

- Post-Doctorate, Harvard School of Dental Medicine,

Boston, USA

- Doctorate in Orthodontics, FOB-USP.

- Master/specialist in Orthodontics, FOB-USP.
24. SILVA FILHO, O. G.; BOAS, M. C.; CAPELOZZA FILHO, L. Rapid maxillary expansion in the primary and mixed dentitions: A cephalometric evaluation. Am. J. Orthod. Dentofacial Orthop. St. Louis, v. 100, no. 2, p. 171-179, Aug. 1991.

25. SUZUKI, A.; TAKAHAMA, Y. A jointed fan-type expander: A newly designed expansion appliance for the upper dental arch of patients with cleft lip and or palate. Cleft Palate J. Pittsburgh, v. 26, no. 3, p. 239-241, 1989

26. TSAI, W. C.; HUANG, C. S.; LIN, C. T.; LIOU, E. J. Dentofacial changes of combined double-hinged rapid maxillary expansion and protraction facemask therapy. J. Taiwan Assoc. Orthod. Taipei, v. 20, no. 2, p. 5-18, 2008.

27. TURLEY, P. K. Orthopedic correction of Class III malocclusion with palatal expansion and custom protraction headgear. J. Clin. Orthod., Boulder, v. 22, no. 5, p. 314-325, May 1988

28. VARDIMON, A. D.; BROSH, T.; SPIEGLER, A.; LIEBERMAN, M.; PITARU, S. Rapid palatal expansion: Part 1. Mineralization pattern of the midpalatal suture in cats. Am. J. Orthod. Dentofacial Orthop., St. Louis, v. 113, no. 4, p. 371-378, Apr. 1998.

29. WANG, Y. C.; CHANG, P. M. S.; LIOU, E. J. Opening of circumaxillary sutures by alternate rapid maxillary expansions and constrictions. Angle Orthod., Appleton, v. 79, no. 2, p. 230-234, Mar. 2009

30. WERTZ, R. A. Skeletal and dental changes accompanying rapid midpalatal suture opening. Am. J. Orthod., St. Louis, v. 58 , no. 1, p. 41-66, July 1970.

\section{Gerson Luiz Ulema Ribeiro}

- Professor, Specialization course in Orthodontics and Facial Orthopedics, UFSC.

- Professor, undergraduate and graduate programs, UFSC.

- Doctor in Orthodontics, UFRJ.

- Master in Orthodontics, UFRJ.

- Licensed by the Brazilian Board of Orthodontics and Facial Orthopedics.

\section{Ricardo Machado Cruz}

- Full Professor, Orthodontics, UNIP/Brasília.

- Doctor in Animal Biology/Genetics, UnB.

- Master in Orthodontics and Facial Orthopedics, FOUFRJ.

- Licensed by the Brazilian Board of Orthodontics and Facial Orthopedics.

\section{Contact:}

Eric Liou

E-mail: lioueric@ms19.hinet.net 